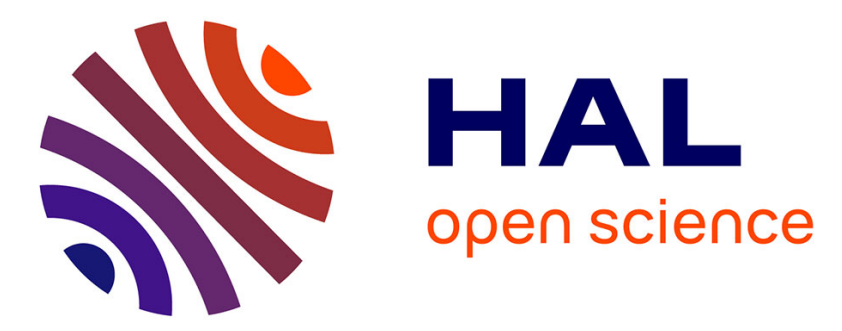

\title{
Exploring the Synthesis of New \\ 1-(4-Substitutedphenylamino) imidazo[1,5-a]indol-3-one Derivatives as Cyclized Analogs of Leucettines
}

Guillaume Burgy, Emmanuelle Limanton, François Carreaux, Emilie Durieu, Laurent Meijer, Jean-Pierre Bazureau

\section{To cite this version:}

Guillaume Burgy, Emmanuelle Limanton, François Carreaux, Emilie Durieu, Laurent Meijer, et al.. Exploring the Synthesis of New 1-(4-Substitutedphenylamino) imidazo[1,5-a]indol-3-one Derivatives as Cyclized Analogs of Leucettines. Journal of Applied Pharmaceutical Science, 2014, 4 (6), pp.25 32. 10.7324/JAPS.2014.40604 . hal-01116022

HAL Id: hal-01116022

https://hal-univ-rennes1.archives-ouvertes.fr/hal-01116022

Submitted on 12 Feb 2015

HAL is a multi-disciplinary open access archive for the deposit and dissemination of scientific research documents, whether they are published or not. The documents may come from teaching and research institutions in France or abroad, or from public or private research centers.
L'archive ouverte pluridisciplinaire HAL, est destinée au dépôt et à la diffusion de documents scientifiques de niveau recherche, publiés ou non, émanant des établissements d'enseignement et de recherche français ou étrangers, des laboratoires publics ou privés. 


\title{
Exploring the Synthesis of New 1-(4-Substitutedphenylamino) imidazo[1,5-a]indol-3-one Derivatives as Cyclized Analogs of Leucettines
}

\author{
Guillaume Burgy, ${ }^{a, b}$ Emmanuelle Limanton, ${ }^{a}$ François Carreaux, ${ }^{a}$ Emilie Durieu, ${ }^{b}$ Laurent Meijer, ${ }^{\mathrm{b}}$ and \\ Jean-Pierre Bazureau ${ }^{\mathrm{a} *}$ \\ ${ }^{a}$ Université de de Rennes 1, Institut des Sciences Chimiques de Rennes ISCR UMR CNRS 6226, groupe Ingénierie Chimique et Molécules pour le Vivant \\ (ICMV), Bât. 10 A, Campus de Beaulieu, CS 74205, 263 Avenue du Général Leclerc, 35042 Rennes Cedex, France. ${ }^{b}$ ManRos Therapeutics, Hôtel de \\ Recherche, Centre de Perharidy, 29680 Roscoff, France.
}

\begin{tabular}{l} 
ARTICLE INFO \\
\hline Article history: \\
Received on: $09 / 04 / 2014$ \\
Revised on: $23 / 04 / 2014$ \\
Accepted on: $26 / 05 / 2014$ \\
Available online: $28 / 06 / 2014$ \\
\hline Key words: \\
imidazo[1,5- $a$ ]indol-3-one, \\
thiourea, isothiorurea, \\
intramolecular, sulphur/ \\
nitrogen displacement, protein \\
kinase, DYRKs, CLKs, \\
Leucettines.
\end{tabular}

\section{INTRODUCTION}

Leucettamine B, a natural marine alkaloid comprising a 2-aminoimidazoline-4-one scaffold, was isolated in 1993 from the sponge Leucetta microraphis Haeckel (Calcarea) of the Argulpelu Reef in Palau (Chan et al., 1993). Several total synthesis of Leucettamine B have been reported (Molina et al., 1994, Roué et al., 1999, Chérouvrier et al., 2001 and 2002, Debdab et al., 2009). Other marine natural products containing the 2-aminoimidazoline4-one core, such as polyandrocarpamine A (Cimino et al., 1982), hymenialdisine (Meijer et al., 2000, Xu et al., 1997, and Papeo et al., 2005) and zorrimidazolone (Aiello et al., 2011), are subject to intensive research by organic chemists, biochemists and biologists.

\footnotetext{
* Corresponding Author

Jean-Pierre BAZUREAU, University of Rennes 1

jean-pierre.bazureau@univ-rennes1.fr
}

Among these molecules, $(Z)$ hymenialdisine was identified as nanomolar inhibitor of various protein kinases (glycogen synthase kinase $3 \beta$ (GSK3 $\beta$, casein kinase 1 (CK1) and different cyclindependent kinases (CDKs) (Wan et al., 2004).

Protein kinases catalyze phosphorylation on serine, threonine and tyrosine residues and regulate protein functions, stability and localization. They constitute very attractive therapeutic targets for the pharmaceutical industry in the search for new clinical drugs.

Recently our group reported the patented synthesis of leucettamine B derivatives (Bazureau et al., 2009), collectively named leucettines, as low molecular weight inhibitors (Debdab et al., 2011 and Tahtouh et al., 2012) of DYRKs (dual specificity, tyrosine phosphorylation regulated kinases) (Aranda et al., 2011) and CLKs (cdc2-like kinases) (Hagiwara et al., 2005), two families of kinase involved in alternative pre-mRNA splicing and Alzheimer's disease/Down syndrome. 
A detailed structure/activity relationship (SAR) study led to the selection of leucettine L41 (Figure 1) as a potent inhibitor of DYRKs and CLKs. To understand the kinase/inhibitor selectivities and to generate models for structure-based optimization, leucettine L41, was co-crystallized with DYRK1A and found to bind in the ATP pocket of this kinase by two direct polar interactions and hydrogen bonds (Debdab et al., 2011). Considering these biological results, particularly the hydrogen bonding network in the co-crystal structure, it was of interest to explore the building of 1-phenylamino imidazo[1,5- $a$ ]indol-3-one (Figure 1) which can be considered as an analog of leucettine L41 obtained by the ring closure of $\mathrm{N}-\mathrm{C}$ atoms between the $\mathrm{N}-1$ position of the 2-aminoimidazoline-4-one platform and the C-6 position of the 1,3-benzodioxol-5-ylidene moiety. Here, we describe the synthesis of new 2-phenylamino imidazo[1,5- $a$ ]indol3 -ones without substituents on the indolone moiety and evaluate their effects on five purified protein kinases. leucettamine B

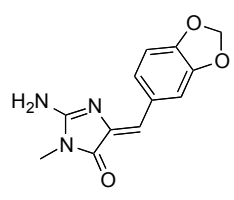

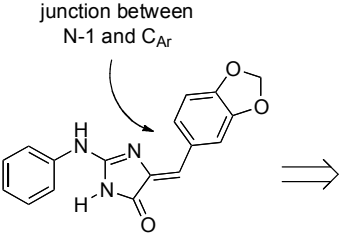

leucettine $\mathrm{L} 41$

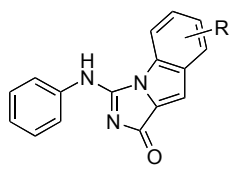
1-phenylamino
idazo[1,5-a]indol-3-one
Fig. 1: Leucettamine B, Leucettine L41 and cyclized derivatives.

\section{MATERIALS AND METHOD}

\section{Materials and instruments}

All reagents and solvents were purchased from Acros, Aldrich Chimie, and Fluka France and were used without further purification. Solvents were evaporated with a BUCHI rotary evaporator. Melting points were determined on a Kofler melting point apparatus and were uncorrected. ${ }^{1} \mathrm{H}$ NMR spectra were recorded on BRUKER AC $300 \mathrm{P}(300 \mathrm{MHz})$ spectrometer, ${ }^{13} \mathrm{C}$ NMR spectra on BRUKER AC $300 \mathrm{P}$ (75 MHz) spectrometer. Chemical shifts are expressed in parts per million downfield from tetramethylsilane as an internal standard. Data are given in the following order: $d$ value, multiplicity ( $\mathrm{s}$, singlet; $\mathrm{d}$, doublet; $\mathrm{t}$, triplet; q, quartet; m, multiplet; br, broad), number of protons, coupling constants $J$ is given in Hertz. The mass spectra (HRMS) were taken respectively on a MS/MS ZABSpec Tof Micromass (EBE TOF geometry) at an ionizing potential of $8 \mathrm{eV}$ and on a VARIAN MAT 311 at an ionizing potential of $70 \mathrm{eV}$ in the "Centre Régional de Mesures Physiques de l'Ouest" (CRMPO, Rennes). Elemental analyses were performed on a Carlo Erba 1106 apparatus.

\section{Methods}

Standard procedure for the synthesis of $\mathrm{N}$-carbamothioyl-1Hindole-2-carboxamide $6(a-f)$ and N-carbothioyl-1H-indole-2carboxamide $6(f, g)$.

In a $50 \mathrm{ml}$ two-necked round-bottomed flask provided with a magnetic stirrer and condenser, a suspension of commercial indole-2-carboxylic acid $\mathbf{1}$ ( $1 \mathrm{~g}, 6.2 \mathrm{mmol})$ was vigorously stirred at room temperature in $25 \mathrm{ml}$ of benzene. To this mixture was added dropwise phosphorous trichloride $[0.85 \mathrm{~g}, 0.54 \mathrm{ml}, 6.2$ mmol for compounds $\mathbf{6}(\mathbf{a}-\mathbf{e})$ or $1.7 \mathrm{~g}, 1.08 \mathrm{ml}, 12.4 \mathrm{mmol}$ for compounds $\mathbf{6}(\mathbf{f}, \mathbf{g})$ ] during $30 \mathrm{~min}$. at $25^{\circ} \mathrm{C}$ under a stream of $\mathrm{Ar}$. The reaction mixture was heated in oil bath at $80^{\circ} \mathrm{C}$ during $1 \mathrm{hr}$. After cooling down to room temperature, the reaction mixture was filtered on a Buchner funnel (porosity $\mathrm{N}^{\circ} 4$ ) and the resulting filtrate was concentrated until a final volume of $5 \mathrm{ml}$ in a rotary evaporator under reduced pressure. This concentrated solution was poured in a $50 \mathrm{ml}$ round bottomed flask provided with a magnetic stirrer and condenser. To this solution were added successively 30 $\mathrm{ml}$ of acetone p.a. and potassium thiocyanate $(603 \mathrm{mg}, 6.2 \mathrm{mmol})$. This suspension was stirred at $25^{\circ} \mathrm{C}$ during $1 \mathrm{hr}$ and primary amine 4 (6.2 $\mathrm{mmol})$ or morpholine $\mathbf{5 a}$ or 4-methylpiperazine $\mathbf{5 b}$ (6.2 mmol) was added in one portion. The reaction mixture was stirred vigorously at $25^{\circ} \mathrm{C}$ during $1 \mathrm{hr}$, then the solvent was removed in a rotary evaporator under reduced pressure. The resulting crude oil crystallized at standing room temperature that gave the desired product $\mathbf{6}$ as yellowish powder, which was submitted to purification by recrystallization in absolute ethanol (1-3 $\mathrm{ml})$.

N-(4-Methylphenylcarbamothioyl)-1H-indole-2-carboxamide (6a)

Compound 6a was prepared in $9 \%$ yield $(173 \mathrm{mg})$ from p-toluidine $4 \mathrm{a}(628 \mathrm{mg}, 598 \mu \mathrm{l}, 6.2 \mathrm{mmol})$ according to the standard procedure. $\mathrm{Mp}=200-202^{\circ} \mathrm{C} .{ }^{1} \mathrm{H}$ NMR $\left(\mathrm{DMSO}-d_{6}\right) \delta$ : 2.32 (s, 3H), 7.09 (dd, 1H, $J=7.4,0.9 \mathrm{~Hz}, \mathrm{Ar}), 7.22$ (d, 2H, $J=$ $7.7 \mathrm{~Hz}, \mathrm{Ar}), 7.25-7.35$ (m, 1H, Ar), 7.49 (d, 1H, $J=8.4 \mathrm{~Hz}, \mathrm{Ar})$, 7.55 (d, 2H, $J=7.7 \mathrm{~Hz}, \operatorname{Ar}), 7.68$ (d, 1H, $J=7.8 \mathrm{~Hz}, \operatorname{Ar}), 7.78$ (s, 1H, Ar), 11.48 (br s, 1H, NH), 12.07 (br s, 1H, NH), 12.58 (br s, $1 \mathrm{H}, \mathrm{NH}) .{ }^{13} \mathrm{C}$ NMR (DMSO-d $\left.d_{6}\right) \delta: 20.57\left(\mathrm{CH}_{3}\right), 108.50,112.58$, $120.36,122.43,124.28,125.21,126.75,128.40,129.06,135.46$, 135.61, 137.78, $161.42(\mathrm{C}=\mathrm{O}), 178.82(\mathrm{C}=\mathrm{S}) . \quad \mathrm{HRMS}, m / z$ : 332.0835 found (calculated for $\mathrm{C}_{17} \mathrm{H}_{15} \mathrm{~N}_{3} \mathrm{ONaS}[\mathrm{M}+\mathrm{Na}]^{+}$requires 332.0839).

\section{$N$-(Phenylcarbamothioyl)-1H-indole-2-carboxamide (6b)}

Compound $\mathbf{6 b}$ was prepared in $9 \%$ yield $(165 \mathrm{mg})$ from aniline 4b (578 mg, $567 \mu \mathrm{l}, 6.2 \mathrm{mmol})$ according to the standard procedure. $\mathrm{Mp}=201-203^{\circ} \mathrm{C}$. ${ }^{1} \mathrm{H}$ NMR $\left(\mathrm{DMSO}-d_{6}\right) \delta: 7.05-7.18$ (m, 1H, Ar), 7.24-7.38 (m, 3H, Ar), 7.38-7.52 (m, 3H, Ar), 7.69 (d, 2H, $J=7.8 \mathrm{~Hz}, \mathrm{Ar}), 7.81$ (s, 1H), 11.50 (br s, 1H, NH), 12.00 (br s, $1 \mathrm{H}, \mathrm{NH}), 12.63$ (br s, $1 \mathrm{H}, \mathrm{NH}) .{ }^{13} \mathrm{C}$ NMR (DMSO- $\left.d_{6}\right) \delta$ : $108.52,112.58,120.38,122.46,124.39,125.25,126.28,126.75$, $127.51,128.65,130.16,137.81,138.01,141.25,161.43(\mathrm{C}=\mathrm{O})$, $178.93(\mathrm{C}=\mathrm{S})$. HRMS, $m / z: 318.0676$ found (calculated for $\mathrm{C}_{16} \mathrm{H}_{13} \mathrm{~N}_{3} \mathrm{ONaS}[\mathrm{M}+\mathrm{Na}]^{+}$requires 318.0671).

$N$-[(4-Fluorophenyl)carbamothioyl]-1H-indole -2- carboxamide (6c)

Compound $\mathbf{6 c}$ was prepared in $18 \%$ yield $(350 \mathrm{mg})$ from 4-fluoroaniline $4 \mathrm{c}(690 \mathrm{mg}, 588 \mu \mathrm{l}, 6.2 \mathrm{mmol})$ according to the standard procedure. $\mathrm{Mp}=199-201{ }^{\circ} \mathrm{C} .{ }^{1} \mathrm{H}$ NMR $\left(\mathrm{DMSO}-d_{6}\right) \delta$ : 7.05-7.13 (m, 1H, Ar), 7.16-7.34 (m, 4H, Ar), 7.49 (d, 1H, $J=8.7$ 
$\mathrm{Hz}, \mathrm{Ar}), 7.63-7.72(\mathrm{~m}, 2 \mathrm{H}, \mathrm{Ar}), 7.80(\mathrm{~s}, 1 \mathrm{H}, \mathrm{Ar}), 11.53(\mathrm{~s}, 1 \mathrm{H}$, $\mathrm{NH}), 11.99(\mathrm{~s}, 1 \mathrm{H}, \mathrm{NH}), 12.50(\mathrm{~s}, 1 \mathrm{H}, \mathrm{NH}) .{ }^{13} \mathrm{C}$ NMR (DMSO- $\left.d_{6}\right)$ $\delta: 108.52,109.69,112.58,114.94,120.38,122.46,125.25,126.75$, $126.95,127.06,131.29,132.12,132.24,137.81,161.35(\mathrm{C}=\mathrm{O})$, $179.52(\mathrm{C}=\mathrm{S}$ ). HRMS, $\mathrm{m} / \mathrm{z}$ : 336.0590 found (calculated for $\mathrm{C}_{16} \mathrm{H}_{12} \mathrm{~N}_{3} \mathrm{O}^{19} \mathrm{FNaS}[\mathrm{M}+\mathrm{Na}]^{+}$requires 336.0577).

\section{$N$-[(3-Fluorophenyl)carbamothioyl]-1H-indole-2-carboxamide} (6d)

Compound 6d was prepared in $75 \%$ yield $(1.46 \mathrm{~g})$ from 3-fluoroaniline $4 d$ (690 mg, $595 \mu \mathrm{l}, 6.2 \mathrm{mmol})$ according to the standard procedure. $\mathrm{Mp}=202-203^{\circ} \mathrm{C} .{ }^{1} \mathrm{H}$ NMR $\left(\mathrm{DMSO}-d_{6}\right) \delta$ : 7.15 (dd, 1H, $J=7.4,1.1 \mathrm{~Hz}, \mathrm{Ar}), 7.22$ (d, 1H, $J=7.7 \mathrm{~Hz}, \mathrm{Ar})$, 7.25-7.30 (m, 1H, Ar), 7.33-7.49 (m, 3H, Ar), 7.55 (m, 1H, Ar), 7.65 (d, 1H, $J=7.8 \mathrm{~Hz}, \mathrm{Ar}), 7.70$ (s, 1H, Ar), 11.48 (br s, 1H, $\mathrm{NH}), 12.00$ (br s, 1H, NH), 12.50 (br s, $1 \mathrm{H}, \mathrm{NH}) .{ }^{13} \mathrm{C}$ NMR $\left(\mathrm{DMSO}-d_{6}\right) \delta$ : $108.62,109.21,112.18,114.75,120.47,122.42$, $125.45,126.72,126.98,127.00,131.20,132.05,132.21,137.74$, $161.35 \quad(\mathrm{C}=\mathrm{O}), \quad 179.42 \quad(\mathrm{C}=\mathrm{S}) . \quad \mathrm{HRMS}, \quad m / z: 336.0584$ found (calculated for $\mathrm{C}_{16} \mathrm{H}_{12} \mathrm{~N}_{3} \mathrm{O}^{19} \mathrm{FNaS}[\mathrm{M}+\mathrm{Na}]^{+}$requires 336.0576).

\section{$N$-(Phenylmethylcarbamothioyl)-1H-indole-2-carboxamide (6e)}

Compound 6e was prepared in $80 \%$ yield $(1.53 \mathrm{~g})$ from benzylamine $4 \mathrm{e}(665 \mathrm{mg}, 679 \mu \mathrm{l}, 6.2 \mathrm{mmol})$ according to the standard procedure. $\mathrm{Mp}=196-198^{\circ} \mathrm{C}$. ${ }^{1} \mathrm{H}$ NMR $\left(\mathrm{DMSO}-d_{6}\right) \delta$ : 4.63 (s, 2H, $\mathrm{CH}_{2} \mathrm{Ar}$ ), 7.12-7.22 (m, 1H, Ar), 7.29-7.38 (m, 3H, Ar), 7.42-7.52 (m, 3H, Ar), 7.73 (d, 2H, J= $7.8 \mathrm{~Hz}$, Ar), 7.80 (s, 1H, Ar), 11.58 (br s, 1H, NH), 11.94 (br s, 1H, NH), 12.60 (br s, 1H, $\mathrm{NH}) .{ }^{13} \mathrm{C}$ NMR (DMSO- $\left.d_{6}\right) \delta$ : $55.32\left(\mathrm{CH}_{2}\right), 108.52,112.58$, $120.28,122.66,124.49,125.24,126.09,126.71,127.62,128.64$, 131.01, 137.42, 138.11, 141.21, $161.12(\mathrm{C}=\mathrm{O}), 178.02(\mathrm{C}=\mathrm{S})$. HRMS, $m / z$ : 332.0941 found (calculated for $\mathrm{C}_{17} \mathrm{H}_{15} \mathrm{~N}_{3} \mathrm{ONaS}$ $[\mathrm{M}+\mathrm{Na}]^{+}$requires 332.0936$)$.

\section{$\mathrm{N}$-(Morpholine-4-carbothioyl)-1H-indole-2-carboxamide (6f)}

Compound $6 \mathbf{f}$ was prepared in $78 \%$ yield $(1.40 \mathrm{~g})$ from morpholine 5a (541 mg, $546 \mu \mathrm{l}, 6.2 \mathrm{mmol}$ ) according to the standard procedure. $\mathrm{Mp}=180-182^{\circ} \mathrm{C}$. ${ }^{1} \mathrm{H}$ NMR (DMSO- $d_{6}$ ) $\square$ : 3.75 (s, 4H, $\left.\mathrm{CH}_{2}\right), 3.72\left(\mathrm{~s}, 4 \mathrm{H}, \mathrm{CH}_{2}\right), 7.32$ (d, 1H, J= $\left.7.7 \mathrm{~Hz}, \mathrm{Ar}\right)$, 7.35-7.43 (m, 2H, Ar), 7.68 (d, 1H, J= $7.8 \mathrm{~Hz}, \mathrm{Ar}), 7.80$ (s, 1H, Ar), 11.50 (br s, 1H, NH), 12.52 (br s, 1H, NH). HRMS, $m / z$ : 312.3430 found (calculated for $\mathrm{C}_{14} \mathrm{H}_{15} \mathrm{~N}_{3} \mathrm{O}_{2} \mathrm{NaS}[\mathrm{M}+\mathrm{Na}]^{+}$requires 312.3426).

$N$-[(4-Methylpiperazine)-4-carbothioyl]-1H-indole-2-carboxamide (6g)

Compound $6 \mathrm{~g}$ was prepared in $75 \%$ yield $(1.41 \mathrm{~g})$ from 4-methylpiperazine $\mathbf{5 b}(628 \mathrm{mg}, 695 \mu \mathrm{l}, 6.2 \mathrm{mmol})$ according to the standard procedure. $\mathrm{Mp}=190-192^{\circ} \mathrm{C} .{ }^{1} \mathrm{H}$ NMR $\left(\mathrm{DMSO}-d_{6}\right) \delta$ : 2.72 (s, 3H, Me), 3.75 (t, 4H, $\left.\mathrm{CH}_{2}\right), 3.98\left(\mathrm{t}, 4 \mathrm{H}, \mathrm{CH}_{2}\right), 7.30(\mathrm{~d}, 1 \mathrm{H}$, $J=7.7 \mathrm{~Hz}, \mathrm{Ar}), 7.45-7.53(\mathrm{~m}, 2 \mathrm{H}, \mathrm{Ar}), 7.60(\mathrm{~d}, 1 \mathrm{H}, J=7.8 \mathrm{~Hz}$, Ar), 7.75 (s, 1H, Ar), 11.42 (br s, 1H, NH), 12.42 (br s, 1H, NH). HRMS, $m / z$ : 325.3846 found (calculated for $\mathrm{C}_{15} \mathrm{H}_{18} \mathrm{~N}_{4} \mathrm{ONaS}$ $[\mathrm{M}+\mathrm{Na}]^{+}$requires 325.3844$)$.
Standard procedure for the synthesis of methylsulfanyl derivatives 7(a-g).

To a solution of compound $\mathbf{6}(1.81 \mathrm{mmol})$ in acetone p.a. $(5 \mathrm{ml})$ mixed in a $50 \mathrm{ml}$ round-bottomed flask provided with a magnetic stirrer and a condenser, was added successively methyl iodide MeI (770 mg, $335 \mu \mathrm{l}, 5.43 \mathrm{mmol}, 3$ equiv) and anhydrous potassium carbonate $\mathrm{K}_{2} \mathrm{CO}_{3}(250 \mathrm{mg}, 1.81 \mathrm{mmol})$. This reaction mixture was heated at $56^{\circ} \mathrm{C}$ in oil bath during 60 min. under vigorous magnetic stirring. After cooling down to room temperature, $35 \mathrm{ml}$ of deionized water was poured in the reaction mixture, then the resulting suspension was stored in a refrigerator $\left(4^{\circ} \mathrm{C}\right)$ during $12 \mathrm{hr}$. The crystallized compound 7 was collected by filtration on a Buchner funnel (porosity $\left.\mathrm{N}^{\circ} 4\right)$ and was dried under high vacuum $\left(10^{-2}\right.$ Torr) at $25^{\circ} \mathrm{C}$ for $1 \mathrm{hr}$. The product 7 was further used without purification.

$\mathrm{N}$-[(4-Methylphenylamino)methylsulfanyl -methylene]-1H-indole2-carboxamide (7a)

Compound 7a was prepared in $66 \%$ yield $(386 \mathrm{mg}$ ) from $\mathrm{N}$-(4-methylphenylcarbamothioyl)- $1 H$-indole-2-carboxamide $\quad$ 6a (560 $\mathrm{mg}, 1.81 \mathrm{mmol})$ according to the standard procedure. $\mathrm{Mp}=$ 152-154 ${ }^{\circ}$ C. Yellowish Powder. ${ }^{1} \mathrm{H}$ NMR (DMSO- $d_{6}$ ) $\delta: 2.32$ (s, $3 \mathrm{H}, \mathrm{Me}_{\mathrm{Ar}}$ ), 2.52 (s, 3H, SMe), 6.97-7.06 (m, 1H, Ar), $7.12(\mathrm{~s}, 1 \mathrm{H}$, Ar), 7.17-7.26 (m, 3H, Ar), 7.37 (d, 2H, $J=8.0 \mathrm{~Hz}, \mathrm{Ar}), 7.45$ (d, $1 \mathrm{H}, J=8.3 \mathrm{~Hz}, \mathrm{Ar}$ ), 7.63 (d, 1H, $J=7.8 \mathrm{~Hz}, \mathrm{Ar}), 11.17$ (br s, $1 \mathrm{H}$, NH), 11.51 (br s, 1H, NH). ${ }^{13} \mathrm{C}$ NMR (DMSO- $\left.d_{6}\right) \delta: 14.27\left(\mathrm{Me}_{\mathrm{Ar}}\right)$, 20.55 (SMe), 106.99, 112.46, 119.73, 121.87, 123.93, 124.68, $129.43,127.14,134.92,135.17,135.89,137.35,160.02(\mathrm{C}=\mathrm{O})$. HRMS, $m / z$ : 346.0988 found (calculated for $\mathrm{C}_{18} \mathrm{H}_{17} \mathrm{~N}_{3} \mathrm{ONaS}$ $[\mathrm{M}+\mathrm{Na}]^{+}$requires 346.0984$)$.

N-[(Phenylamino)methylsulfanyl- methylene]- 1H-indole-2carboxamide (7b)

Compound $7 \mathbf{b}$ was prepared in $52 \%$ yield $(291 \mathrm{mg})$ from $\mathrm{N}$-(phenylcarbamothioyl)- $1 H$-indole-2-carboxamide $6 \mathbf{b}(534 \mathrm{mg}$, $1.81 \mathrm{mmol}$ ) according to the standard procedure. $\mathrm{Mp}=150-152^{\circ} \mathrm{C}$. Yellowish Powder. ${ }^{1} \mathrm{H}$ NMR (DMSO- $\left.d_{6}\right) \delta: 2.52$ (s, 3H, SMe), 6.98-7.14 (m, 2H, Ar), 7.18-7.30 (m, 3H, Ar), 7.37-7.46 (m, 3H, Ar), 7.52 (d, 2H, $J=8.0 \mathrm{~Hz}, \mathrm{Ar}$ ), 11.03 (br s, 1H, NH), 11.54 (br s, $1 \mathrm{H}, \mathrm{NH}) .{ }^{13} \mathrm{C}$ NMR (DMSO- $d_{6}$ ) $\delta: 22.63$ (SMe), 100.23, 106.99, $112.46,119.81,121.78,123.91,124.68,127.18,129.43,134.90$, 135.21, 135.96, 137.35, $160.02(\mathrm{C}=\mathrm{O})$. HRMS, m/z: 332.0833 found (calculated for $\mathrm{C}_{17} \mathrm{H}_{15} \mathrm{~N}_{3} \mathrm{ONaS} \quad[\mathrm{M}+\mathrm{Na}]^{+}$requires 332.0828).

$N$-[(4-Fluorophenylamino)methylsulfanyl-methylene]-1H-indole2-carboxamide (7c)

Compound 7c was prepared in $69 \%$ yield $(409 \mathrm{mg}$ ) from $N$-[(4-fluorophenyl)carbamothioyl]- $1 H$-indole-2-carboxamide $\mathbf{6 c}$ (567 $\mathrm{mg}, 1.81 \mathrm{mmol}$ ) according to the standard procedure. $\mathrm{Mp}=$ 148- $150^{\circ} \mathrm{C}$. Yellowish Powder. ${ }^{1} \mathrm{H}$ NMR (DMSO- $d_{6}$ ) $\delta: 2.52$ (s, 3H, SMe), 7.41-7.50 (m, 2H, Ar), 7.54 (d, 2H, $J=6.2 \mathrm{~Hz}$, Ar), 7.62 (d, 2H, $J=7.7 \mathrm{~Hz}, \mathrm{Ar}), 7.77-7.84$ (m, 2H, Ar), 7.98 (d, 1H, $J$ 
$=7.6 \mathrm{~Hz}, \mathrm{Ar}), 10.90(\mathrm{br} \mathrm{s}, 1 \mathrm{H}, \mathrm{NH}), 11.54(\mathrm{br} \mathrm{s}, 1 \mathrm{H}, \mathrm{NH}) \cdot{ }^{13} \mathrm{C}$ NMR (DMSO- $d_{6}$ ) $\delta: 32.77$ (SMe), 106.26, 115.49, 115.79, 121.91, $123.99,131.79,132.89,133.01,134.81,135.05,137.36,160,08$ $(\mathrm{C}=\mathrm{O})$. HRMS, $\mathrm{m} / \mathrm{z}$ : 350.0736 found (calculated for $\mathrm{C}_{17} \mathrm{H}_{14} \mathrm{~N}_{3} \mathrm{O}^{19} \mathrm{FNaS}[\mathrm{M}+\mathrm{Na}]^{+}$requires 350.0733$)$.

$N$-[(3-Fluorophenylamino) methylsulfanyl-methylene]-1H-indole2-carboxamide (7d)

Compound 7d was prepared in $62 \%$ yield $(367 \mathrm{mg})$ from $\quad N$-[(3-fluorophenyl)carbamothioyl]-1 $H$-indole-2carboxamide 6d $(567 \mathrm{mg}, 1.81 \mathrm{mmol})$ according to the standard procedure. $\mathrm{Mp}=149-151^{\circ} \mathrm{C}$. Yellowish Powder. ${ }^{1} \mathrm{H}$ NMR (DMSO- $d_{6}$ ) $\delta: 2.53$ (s, 3H, SMe), 7.02 (s, 1H, Ar), 7.107.37 (m, 6H, Ar), 7.45 (d, 1H, $J=8.3 \mathrm{~Hz}, \mathrm{Ar}), 7.63(\mathrm{~d}, 1 \mathrm{H}, J=7.8$ $\mathrm{Hz}, \mathrm{Ar}$ ), 11.03 (br s, 1H, NH), 11.55 (br s, $1 \mathrm{H}, \mathrm{NH}) .{ }^{13} \mathrm{C} \mathrm{NMR}$ $\left(\mathrm{DMSO}-d_{6}\right)$ 8: 22.61 (SMe), 100.30, 106.99, 112.36, 119.84, $121.68,123.86,124.10,127.11,129.43,134.90,135.18,135.95$, 137.45, $160.05(\mathrm{C}=\mathrm{O})$. HRMS, $\mathrm{m} / z$ : 350.0738 found (calculated for $\mathrm{C}_{17} \mathrm{H}_{14} \mathrm{~N}_{3} \mathrm{O}^{19} \mathrm{FNaS}[\mathrm{M}+\mathrm{Na}]^{+}$requires 350.0733 ).

\section{N-[(Phenylmethylamino)methylsulfanyl-methylene]-1H-indole-2- carboxamide (7e)}

Compound 7e was prepared in $65 \%$ yield $(380 \mathrm{mg}$ ) from $N$-(phenylmethylcarbamothioyl)- $1 H$-indole-2-carboxamide 6e $(560 \mathrm{mg}, \quad 1.81 \mathrm{mmol})$ according to the standard procedure. $\mathrm{Mp}=152-154^{\circ} \mathrm{C}$. Yellowish Powder. ${ }^{1} \mathrm{H}$ NMR (DMSO- $d_{6}$ ) $\delta: 2.52$ (s, 3H, SMe), 4.60 (s, 2H, $\mathrm{CH}_{2} \mathrm{Ar}$ ), 7.00-7.08 (m, 2H, Ar), 7.16-7.25 (m, 3H, Ar), 7.35-7.42 (m, 3H, Ar), 7.50 (d, 2H, $J=8.0 \mathrm{~Hz}, \mathrm{Ar}$ ), 11.05 (br s, $1 \mathrm{H}, \mathrm{NH}$ ), 11.62 (br s, $1 \mathrm{H}$, $\mathrm{NH}) .{ }^{13} \mathrm{C}$ NMR (DMSO- $\left.d_{6}\right) \delta: 24.63(\mathrm{SMe}), 52.22\left(\mathrm{CH}_{2} \mathrm{Ar}\right)$, $100.34,106.99,112.32,119.87,121.68,123.85,124.10,127.11$, 129.43, 134.90, 135.14, 135.95, 137.45, $160.12(\mathrm{C}=\mathrm{O})$. HRMS, $m / z$ : 346.0990 found (calculated for $\mathrm{C}_{18} \mathrm{H}_{17} \mathrm{~N}_{3} \mathrm{ONaS}[\mathrm{M}+\mathrm{Na}]^{+}$ requires 346.0984).

\section{Methyl N-(1H-indol-2-carbonyl)morpholine-4 -carboximidothioate} (7f)

Compound $7 \mathbf{f}$ was prepared in 59\% yield (324 mg) from $\mathrm{N}$-(morpholine-4-carbothioyl)- $1 \mathrm{H}$-indole-2-carboxamide of (522 $\mathrm{mg}, 1.81 \mathrm{mmol})$ according to the standard procedure. $\mathrm{Mp}=158$ $160^{\circ} \mathrm{C}$. Yellowish Powder. ${ }^{1} \mathrm{H}$ NMR (DMSO- $d_{6}$ ) $\delta: 2.33$ (s, $3 \mathrm{H}$, $\mathrm{SMe}$ ), 3.70 (s, $\left.8 \mathrm{H}, \mathrm{CH}_{2}\right), 6.94$ (s, $\left.1 \mathrm{H}, \mathrm{Ar}\right), 7.01$ (dd, $1 \mathrm{H}, J=11.0$, $3.9 \mathrm{~Hz}, \mathrm{Ar}), 7.12-7.19$ (m, 1H, Ar), $7.41(\mathrm{~d}, 1 \mathrm{H}, J=8.2 \mathrm{~Hz}, \mathrm{Ar})$, 7.58 (d, $1 \mathrm{H}, J=7.9 \mathrm{~Hz}, \mathrm{Ar}$ ), 11.45 (br s, $1 \mathrm{H}, \mathrm{NH})$. HRMS, $m / z$ : 326.0941 found (calculated for $\mathrm{C}_{15} \mathrm{H}_{17} \mathrm{~N}_{3} \mathrm{O}_{2} \mathrm{NaS}[\mathrm{M}+\mathrm{Na}]^{+}$requires 326.0939).

\section{Methyl N-(1H-indol-2-carbonyl)- 4-methylpiperazine-1-} carboximidothioate $(7 \mathrm{~g})$

Compound $7 \mathrm{~g}$ was prepared in $64 \%$ yield (367 $\mathrm{mg}$ ) from $N$-[(4-methylpiperazine)-4-carbothioyl]-1 $H$-indole-2carboxamide $\mathbf{6 g}(547 \mathrm{mg}, 1.81 \mathrm{mmol})$ according to the standard procedure. $\mathrm{Mp}=162-164^{\circ} \mathrm{C}$. Yellowish Powder. ${ }^{1} \mathrm{H}$ NMR (DMSO- $d_{6}$ ) $\delta: 1.69$ (s, 3H, MeN), 3.28 (s, 3H, SMe), 3.61- $3.71(\mathrm{~m}, 4 \mathrm{H}, \mathrm{Ar}), 4.23-4.34(\mathrm{~m}, 4 \mathrm{H}, \mathrm{Ar}), 6.97$ (s, 1H, Ar), 7.197.43 (m, 2H, Ar), 7.45-7.57 (m, 1H, Ar), 7.75 (d, $1 \mathrm{H}, J=8.0 \mathrm{~Hz}$, Ar), $\quad 10.16 \quad(b r \quad s, \quad 1 H, \quad N H)$. HRMS, $m / z: 339.1260$ found (calculated for $\mathrm{C}_{16} \mathrm{H}_{20} \mathrm{~N}_{4} \mathrm{ONaS}[\mathrm{M}+\mathrm{Na}]^{+}$requires 339.1256).

Standard procedure for the synthesis of 1-amino-imidazo[1,5a] indol-3-one derivatives $8(\boldsymbol{a}-\mathbf{g})$.

In a $50 \mathrm{ml}$ round-bottomed flask provided with a magnetic stirrer and condenser was added successively compound $7(3 \mathrm{mmol}), 5 \mathrm{ml}$ of anhydrous dimethylformamide $\mathrm{Me}_{2} \mathrm{NCHO}$ and lithium hydride $\mathrm{LiH}$ [powder, $30 \mathrm{mesh}, 95 \%$ ] $(50 \mathrm{mg}, 6.3$ mmol, 2.1 equiv). The reaction mixture was stirred vigorously at room temperature under a stream of argon during $6 \mathrm{hr}$. After addition of cold deionized water $(35 \mathrm{ml})$, the resulting reaction mixture was stored in a refrigerator $\left(4^{\circ} \mathrm{C}\right)$ during $12 \mathrm{hr}$. The insoluble compound $\mathbf{8}$ was collected by filtration on a Buchner funnel (porosity $\left.\mathrm{N}^{\circ} 4\right)$ and washed with deionized water $(3 \times 10 \mathrm{ml})$. The crude product 8 was purified by recrystallization in absolute ethanol and dried under high vacuum $\left(10^{-2}\right.$ Torr $)$ at $25^{\circ} \mathrm{C}$ for $2 \mathrm{hrs}$ that gave the desired product $\mathbf{8}$ as yellowish powder.

\section{1-(4-Methylphenylamino)imidazo[1,5-a]indol-3-one (8a)}

Compound 8a was prepared in 32\% yield (264 $\mathrm{mg}$ ) from $\mathrm{N}$-[(4-methylphenylamino)methylsulfanyl-methylene]- $1 \mathrm{H}$-indole2-carboxamide 7a $(970 \mathrm{mg}, 3 \mathrm{mmol})$ according to the standard procedure. $\mathrm{Mp}=152-154^{\circ} \mathrm{C} .{ }^{1} \mathrm{H}$ NMR $\left(\mathrm{DMSO}-d_{6}\right) \delta: 2.30(\mathrm{~s}, 3 \mathrm{H}$, $\left.\mathrm{Me}_{\mathrm{Ar}}\right), 6.98(\mathrm{~d}, 2 \mathrm{H}, J=8.2 \mathrm{~Hz}, \mathrm{Ar}), 7.17(\mathrm{~d}, 2 \mathrm{H}, J=8.1 \mathrm{~Hz}, \mathrm{Ar})$, $7.19(\mathrm{~s}, 1 \mathrm{H},=\mathrm{CH}, \mathrm{Ar}), 7.29(\mathrm{dd}, 1 \mathrm{H}, J=7.4,1.6 \mathrm{~Hz}, \mathrm{Ar}), 7.49(\mathrm{dd}$, $1 \mathrm{H}, J=7.4,1.1 \mathrm{~Hz}, 1 \mathrm{H}), 7.80(\mathrm{~d}, 1 \mathrm{H}, J=8.0 \mathrm{~Hz}, \mathrm{Ar}), 7.99(\mathrm{~d}, 1 \mathrm{H}$, $J=8.2 \mathrm{~Hz}, \mathrm{Ar}$ ), 11.22 (br s, $1 \mathrm{H}, \mathrm{NH}) .{ }^{13} \mathrm{C}$ NMR (DMSO- $\left.d_{6}\right) \delta$ : $20.48\left(\mathrm{CH}_{3}\right), 103.75,113.33,122.04,122.94,123.90,126.93$, $129.57,129.64,131.66,132.18,132.76,138.87,143.23,160.36$ (C-3, C=O). HRMS, $m / z$ : 298.0959 found (calculated for $\mathrm{C}_{17} \mathrm{H}_{13} \mathrm{~N}_{3} \mathrm{ONa}[\mathrm{M}+\mathrm{Na}]^{+}$requires 298.0950). Anal. Calcd. for $\mathrm{C}$, 74.17; H, 4.76; N, 15.26. Found: C: 74.11; H, 4.73; N, 15.24 .

\section{1-(Phenylamino)imidazo[1,5-a]indol-3-one ( $8 \boldsymbol{b})$}

Compound $\mathbf{8 b}$ was prepared in $34 \%$ yield $(267 \mathrm{mg}$ ) from $\mathrm{N}$-[(phenylamino)methylsulfany 1-methylene]- $\quad 1 H$-indole-2carboxamide $7 \mathbf{b}(928 \mathrm{mg}, 3 \mathrm{mmol})$ according to the standard procedure. $\mathrm{Mp}=212-214^{\circ} \mathrm{C} .{ }^{1} \mathrm{H}$ NMR $\left(\right.$ DMSO- $\left.d_{6}\right) \delta:$ 7.07-7.17 (m, 3H, Ar), $7.21(\mathrm{~s}, 1 \mathrm{H},=\mathrm{CH}, \mathrm{Ar}), 7.30(\mathrm{dd}, 1 \mathrm{H}, J=7.6,1.4 \mathrm{~Hz}$, Ar), 7.34-7.41 (m, 2H, Ar), 7.50 (dd, $1 \mathrm{H}, J=7.3 \mathrm{~Hz}, \mathrm{Ar}), 7.81$ (d, $1 \mathrm{H}, J=8.0 \mathrm{~Hz}, \mathrm{Ar}$ ), 7.99 (d, $1 \mathrm{H}, J=8.1 \mathrm{~Hz}, \mathrm{Ar}$ ), 11.26 (br s, $1 \mathrm{H}$, $\mathrm{NH}) .{ }^{13} \mathrm{C}$ NMR (DMSO- $\left.d_{6}\right) \delta: 103.88,113.32,122.16,122.99$, 123.83, 123.94, 126.99, 129.08, 129.71, 131.69, 132.22, 145.87, $160.56(\mathrm{C}-3, \mathrm{C}=\mathrm{O})$. HRMS, $\mathrm{m} / \mathrm{z}$ : 284.0979 found (calculated for $\mathrm{C}_{16} \mathrm{H}_{12} \mathrm{~N}_{3} \mathrm{ONa}[\mathrm{M}+\mathrm{Na}]^{+}$requires 284.0902). Anal. Calcd. for $\mathrm{C}$, 73.55; H, 4.24; N, 16.08. Found: C: 73.69; H, 4.26; N, 16.11.

\section{1-(4-Fluorophenylamino)imidazo[1,5-a]indol-3-one (8c)}

Compound $\mathbf{8 c}$ was prepared in $27 \%$ yield $(226 \mathrm{mg}$ ) from $\mathrm{N}$-[(4-fluorophenylamino)methylsulfanyl -methylene]- $1 \mathrm{H}$-indole2-carboxamide $7 \mathrm{c}$ (982 $\mathrm{mg}, 3 \mathrm{mmol}$ ) according to the standard 
procedure. $\mathrm{Mp}=211-213^{\circ} \mathrm{C} .{ }^{1} \mathrm{H}$ NMR $\left(\mathrm{DMSO}-d_{6}\right) \delta: 7.06-7.23$ (m, 5H, Ar), 7.30 (dd, 1H, $J=7.5,1.2 \mathrm{~Hz}, \mathrm{Ar}), 7.49$ (dd, 1H, $J=$ 7.6, $1.8 \mathrm{~Hz}, \mathrm{Ar}), 7.80$ (d, 1H, $J=8.0 \mathrm{~Hz}, \mathrm{Ar}), 7.97$ (d, $1 \mathrm{H}, J=8.2$ $\mathrm{Hz}, \mathrm{Ar}$ ), 11.28 (br s, $1 \mathrm{H}, \mathrm{NH}) .{ }^{13} \mathrm{C}$ NMR (DMSO-d $\left.)_{6}\right) \delta: 104.05$, $113.32,115.51,115.81,123.02,123.64,123.75,123.94,127.02$, $129.65,131.69,132.20,139.58,142.38,157.42,160.33$ (C-3, $\mathrm{C}=\mathrm{O}$ ). HRMS, $\mathrm{m} / \mathrm{z}$ : 302.0703 found (calculated for $\mathrm{C}_{16} \mathrm{H}_{10} \mathrm{~N}_{3} \mathrm{O}^{19} \mathrm{FNa}[\mathrm{M}+\mathrm{Na}]^{+}$requires 302.0700). Anal. Calcd. for $\mathrm{C}$, $68.81 ; \mathrm{H}, 3.61 ; \mathrm{N}, 15.05$. Found: C: 68.89; H, 3.64; N, 15.09 .

\section{1-(3-Fluorophenylamino)imidazo[1,5-a]indol-3-one (8d)}

Compound $8 \mathbf{d}$ was prepared in $52 \%$ yield $(436 \mathrm{mg})$ from $N$-[(3-fluorophenylamino)methylsulfanyl-methylene]-1 $H$-indole-2carboxamide 7d (982 $\mathrm{mg}, 3 \mathrm{mmol}$ ) according to the standard procedure. $\mathrm{Mp}=220-222^{\circ} \mathrm{C}$. ${ }^{1} \mathrm{H}$ NMR $\left(\mathrm{DMSO}-d_{6}\right) \delta: 6.88-7.00$ (m, 3H, Ar), 7.23 (s, 1H, =CH, Ar), 7.26-7.44 (m, 2H, Ar), 7.50 (dd, $1 \mathrm{H}, J=7.3,1.7 \mathrm{~Hz}, \mathrm{Ar}), 7.81$ (d, $1 \mathrm{H}, J=8.0 \mathrm{~Hz}, \mathrm{Ar}), 7.96$ (d, $1 \mathrm{H}, J=8.2 \mathrm{~Hz}, \mathrm{Ar}), 11.35$ (br s, $1 \mathrm{H}, \mathrm{NH}) .{ }^{13} \mathrm{C}$ NMR (DMSO- $d_{6}$ ) $\delta$ : $104.32,109.19,109.49,110.30,110.58,113.30,123.08,123.99$, $127.09,129.69,130.46,131.71,132.23,139.95,148.04,160.37$ $(\mathrm{C}-3, \quad \mathrm{C}=\mathrm{O}$ ). HRMS, $\mathrm{m} / \mathrm{z}$ : 302.0704 found (calculated for $\mathrm{C}_{16} \mathrm{H}_{10} \mathrm{~N}_{3} \mathrm{O}^{19} \mathrm{FNa}[\mathrm{M}+\mathrm{Na}]^{+}$requires 302.0700$)$. Anal. Calcd. for $\mathrm{C}$, 68.81; H, 3.61; N, 15.05. Found: C: 68.86; H, 3.62; N, 15.07.

\section{1-(Phenylmethylamino)imidazo[1,5-a]indol-3-one (8e)}

Compound $8 \mathrm{e}$ was prepared in $22 \%$ yield $(181 \mathrm{mg})$ from $N$-[(phenylmethylamino)methylsulfanyl-methylene $]-1 H$-indole-2carboxamide 7 e $(970 \mathrm{mg}, 3 \mathrm{mmol})$ according to the standard procedure. $\mathrm{Mp}=222-224^{\circ} \mathrm{C} .{ }^{1} \mathrm{H}$ NMR $\left(\mathrm{DMSO}-d_{6}\right) \delta: 4.66(\mathrm{~s}, 2 \mathrm{H}$, $\left.\mathrm{CH}_{2} \mathrm{Ar}\right), 7.13$ (s, 1H, =CH, Ar), 7.19-7.31 (m, 2H, Ar), 7.32-7.53 (m, 5H, Ar), 7.76 (d, 1H, $J=7.7 \mathrm{~Hz}, \mathrm{Ar}), 7.93(\mathrm{~d}, 1 \mathrm{H}, J=7.1 \mathrm{~Hz}$, Ar), 11.60 (br s, $1 \mathrm{H}, \mathrm{NH}) .{ }^{13} \mathrm{C}$ NMR (DMSO- $\left.d_{6}\right) \delta: 51.48\left(\mathrm{CH}_{2}\right)$, $103.02,113.13,122.64,123.74,126.57,126.70,127.31,128.30$, $129.66,131.54,131.96,139.85,140.05,160.33$ (C-3, C=O). HRMS, $m / z$ : 298.0959 found (calculated for $\mathrm{C}_{17} \mathrm{H}_{13} \mathrm{~N}_{3} \mathrm{ONa}$ $[\mathrm{M}+\mathrm{Na}]^{+}$requires 298.0950). Anal. Calcd. for $\mathrm{C}, 74.17 ; \mathrm{H}, 4.76$; N, 15.26. Found: C: 74.21; H, 4.77; N, 15.27.

\section{Biochemistry}

\section{Protein kinase assay buffers}

Buffer A: $10 \mathrm{mM} \mathrm{MgCl}_{2}, 1 \mathrm{mM}$ EGTA, $1 \mathrm{mM}$ DTT, $25 \mathrm{mM}$ Tris$\mathrm{HCl} \mathrm{pH} 7.5,50 \mu \mathrm{g}$ heparin $/ \mathrm{ml}$.

Buffer $B: 60 \mathrm{mM} \beta$-glycerophosphate, $15 \mathrm{mM}$-nitrophenylphosphate, $25 \mathrm{mM}$ Mops (pH 7.2), $5 \mathrm{mM}$ EGTA, $15 \mathrm{mM} \mathrm{MgCl}_{2}, 1$ $\mathrm{mM}$ DTT, $1 \mathrm{mM}$ sodium vanadate, $1 \mathrm{mM}$ phenylphosphate.

\section{Kinase preparations and assays}

Kinase activities for each enzyme were assayed in buffer A or B, with their corresponding substrates, in the presence of $15 \mu \mathrm{M}$ ATP in a final volume of $30 \mu \mathrm{L}$. After 30 min incubation at $30^{\circ} \mathrm{C}$, the reaction was stopped by harvesting, using a FilterMate harvester (Packard), onto P81 phosphocellulose papers (GE Healthcare) which were washed in $1 \%$ phosphoric acid. Scintillation fluid was added and the radioactivity measured in a Packard counter. Blank values were subtracted and activities calculated as pmoles of phosphate incorporated during the $30 \mathrm{~min}$ incubation. The activities were expressed in $\%$ of the maximal activity, i.e. in the absence of inhibitors. Controls were performed with appropriate dilutions of DMSO.

$C D K 5 / p 25$ (human, recombinant) was prepared as previously described (Leclerc et al., 2001). Its kinase activity was assayed in buffer B, with $1 \mathrm{mg}$ histone $\mathrm{H} 1 / \mathrm{ml}$, in the presence of $15 \mu \mathrm{M}\left[\gamma_{-}{ }^{33} \mathrm{P}\right]$ ATP $(3,000 \mathrm{Ci} / \mathrm{mmol} ; 10 \mathrm{mCi} / \mathrm{ml})$ in a final volume of $30 \mu \mathrm{l}$. After $30 \mathrm{~min}$ incubation at $30^{\circ} \mathrm{C}, 25 \mu \mathrm{l}$ aliquots of supernatant were spotted onto $2.5 \times 3 \mathrm{~cm}$ pieces of Whatman P81 phosphocellulose paper, and, $20 \mathrm{~s}$ later, the filters were washed five times (for at least $5 \mathrm{~min}$ each time) in a solution of $10 \mathrm{ml}$ phosphoric acid/liter of water. The wet filters were counted in the presence of $1 \mathrm{ml}$ ACS (Amersham) scintillation fluid.

DYRK1A (rat, recombinant, expressed in Escherichia coli as a GST fusion protein, provided by Dr. W. Becker) was purified by affinity chromatography on glutathione-agarose and assayed as described for CDK5/p25 using myelin basic protein $(1 \mathrm{mg} / \mathrm{ml})$ as a substrate.

Casein kinase $1(C K 1 \delta / \varepsilon)$ (porcine brain, native) was assayed with $0.67 \mu \mathrm{g}$ of CKS peptide (RRKHAAIGpSAYSITA), a CK1 specific substrate obtained from Millegen (Labege, France) (Reinhardt et al., 2007).

$G S K-3 \alpha / \beta$ (porcine brain, native) was assayed, as described for CDK5/p25 but in Buffer A and using a GSK-3 specific substrate (GS-1: YRRAAVPPSPSLSRHSSPHQSpEDEEE) (pS stands for phosphorylated serine) (Primot et al., 2000). GS-1 was synthesized by Millegen (Labege, France).

CLK1 (mouse, recombinant, expressed in Escherichia coli as GST fusion proteins) was assayed in buffer A $(+0.15 \mathrm{mg}$ $\mathrm{BSA} / \mathrm{ml})$ with RS peptide (GRSRSRSRSRSR) (1 $\mu \mathrm{g} /$ assay).

\section{RESULTS AND DISCUSSION}

For the preparation of the cyclized derivative of leucettine L41, the planned retrosynthesis of 1-aminoimidazo[1,5a]indol-3-ones (Figure 2) involved firstly, a ring closure by intramolecular sulphur/nitrogen displacement; secondly, activation of the carbon sulphur double bond by classical $S$-alkylation with an halogenoalcane; thirdly, thiourea synthesis by addition of primary or secondary amine on isothiocyanate function and fourthly, nucleophilic addition of thiocyanate anion on the indole2-carbonyl halide In order to synthesize the desired new 1aminoimidazo[1,5-a]indol-3-ones 8 (Scheme 1), commercial indole-2-carboxylic acid $\mathbf{1}$ was treated successively by phosphorous trichloride (Katritzky et al., 2004) under reflux at $85^{\circ} \mathrm{C}$ during $2 \mathrm{hrs}$ followed by addition of potassium isothiocyanate in acetone at room temperature for a supplementary reaction time of $1 \mathrm{hr}$ (Abu-El-Halawa et al., 2008). Initial attempts to isolate the indole-2-carbonyl isothiocyanate $\mathbf{3}$ for complete caracterization by ${ }^{1} \mathrm{H},{ }^{13} \mathrm{C}$ NMR and HRMS analyses failed. This can be explained by the instability of intermediate 3 in the reaction medium during its preparation (Kutschy et al., 2000). 


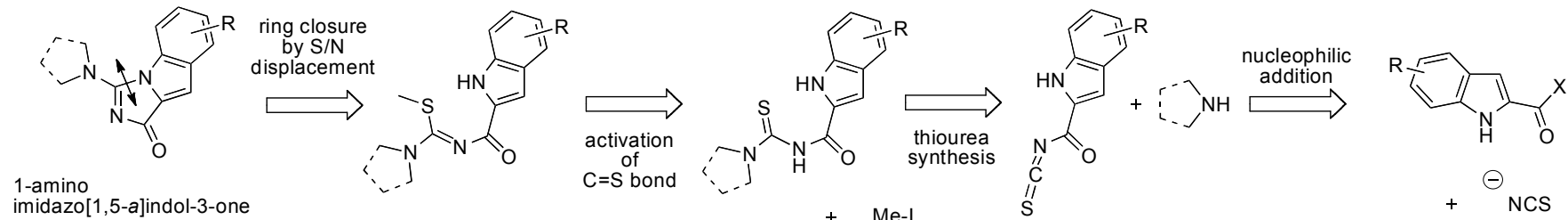

Fig. 2: Retrosynthetic strategy towards new 1 -aminoimidazo[1,5-a]indol-3-ones<smiles>O=C(N=C=S)c1cc2ccccc2[nH]1</smiles>

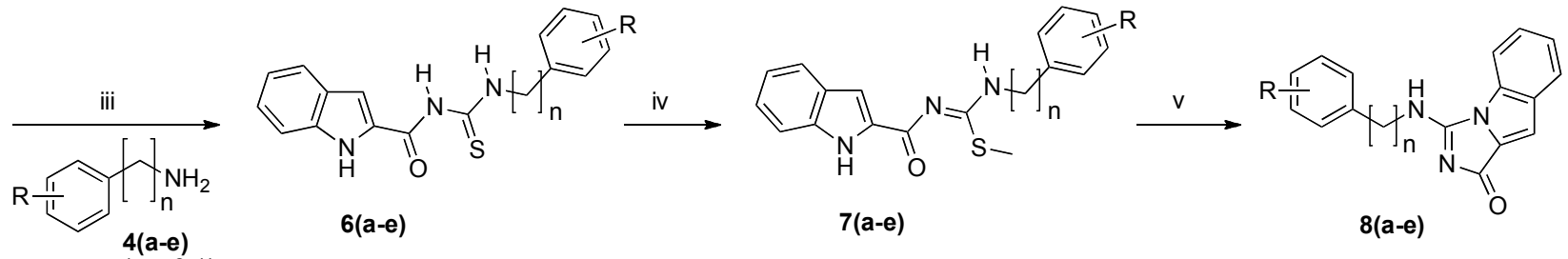
$(\mathrm{n}=0,1)$

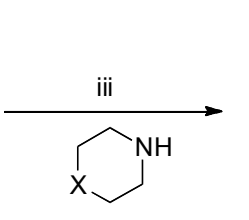

$5(a, b)$<smiles>[X]CCN(CC)C(=S)NC(=O)c1cc2ccccc2[nH]1</smiles>

6(f,g)

$\mathrm{X}=0, \mathrm{NMe}$
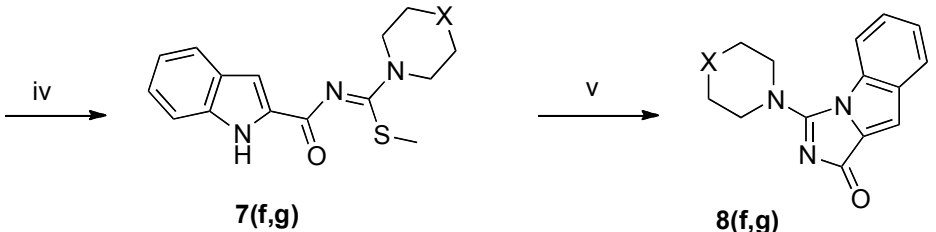

Scheme. 1: Reagents and reaction conditions: (i) $\mathrm{PCl}_{3} 2$ equiv, $\mathrm{C}_{6} \mathrm{H}_{6}, 2 \mathrm{hrs}, 85^{\circ} \mathrm{C}$. (ii) $\mathrm{KSCN} 1$ equiv, acetone, $1 \mathrm{hr}, 25^{\circ} \mathrm{C}$. (iii) $4 \mathrm{or} 51 \mathrm{equiv}, 1 \mathrm{hr}, 25^{\circ} \mathrm{C}$. (iv) MeI 3 equiv, $\mathrm{K}_{2} \mathrm{CO}_{3} 1$ equiv, acetone, $1 \mathrm{hr}$, reflux. (v) LiH 2 equiv, dry DMF, $6 \mathrm{hrs}, 25^{\circ} \mathrm{C}$.

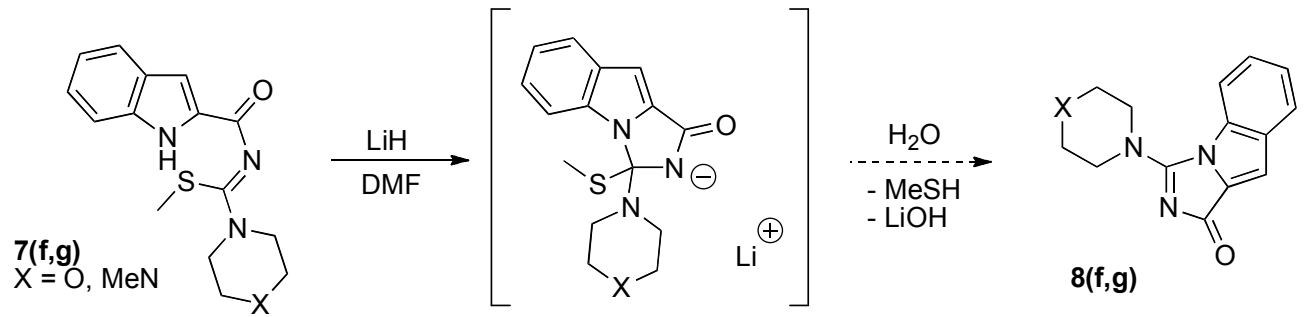

Fig. 3: Possible transient intermediate during reaction of methylsulfanyl isothioureas $\mathbf{7 ( f , g )}$ in the presence of lithium hydride.

To obtain the desired product $N, N^{\prime}$-disubstituted thioureas $\mathbf{6}$ from indole-2-carboxylic acid $\mathbf{1}$ in a reasonable yield, we decided to avoid isolation and purification of the indole-2carbonyl chloride $\mathbf{2}$ and indole-2-carbonyl isothiocyanate $\mathbf{3}$ intermediates due to their instability under the hydrolytic work-up conditions. With the aim of introducing diversity on the $\mathrm{N}-1$ position of the desired 1-aminoimidazo[1,5-a]indol-3-ones $\mathbf{8}$, we examined the reactivity of indole-2-carbonyl isothiocyanate $\mathbf{3}$ with five primary amines $\mathbf{4}(\mathbf{a}-\mathbf{c})$ (i.e. $p$-toluidine $\mathbf{4 a}$, aniline $\mathbf{4 b}$, 4fluoroaniline 4c, 3-fluoroaniline $4 \mathbf{d}$ and benzylamine $4 e$ ) and two polar secondary cyclic amines $\mathbf{5}(\mathbf{a}, \mathbf{b})$ (i.e. morpholine $\mathbf{5 a}$ and $\mathrm{N}$ methylpiperazine $\mathbf{5 b}$ ). The reaction of the intermediate $\mathbf{3}$ with the amines $\mathbf{4}$ and $\mathbf{5}$ afforded the corresponding thioureas 6(ag) as yellowish solids, which were purified by recrystallization from EtOH. As shown in Table 1, the $N, N^{\prime}$-disubstituted thioureas $\mathbf{6}$ were synthesized in low to good yields $(9-80 \%)$.
In order to prepare the desired 1-aminoimidazo[1,5-a]indol-3-ones 8 by cyclization, via intramolecular sulphur/nitrogen displacement, it was necessary to activate the $\mathrm{C}=\mathrm{S}$ bond of the $N, N^{\prime}$-disubstituted thioureas 6 with a halogenoalcane. $S$-alkylation of these $N, N^{\prime}-$ disubstituted thioureas $\mathbf{6}$ was realized with 3 equivalents of methyl iodide in refluxed acetone in the presence of powdered potassium

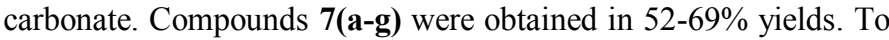
investigate the scope and limitation of the cyclization depicted in Scheme 1, we screened the reactivity of various bases in appropriate solvent $\left(\mathrm{Et}_{3} \mathrm{~N}\right.$, pyridine, piperidine in acetonitrile, tert$\mathrm{BuOK}$ in tert-BuOH, AcONa in $\mathrm{AcOH}, \mathrm{NaH}$ in THF or 1,4dioxane). No cyclization took place and starting compounds were recovered, thus indicating, that the choice of the base and the solvent was essential for successful ring closure. In fact, the lithium hydride (2 equivalents) in dry dimethylformamide mediated cyclization of compounds 7 . This cyclization proceeded 
via intramolecular nucleophilic attack of the deprotonated indole nitrogen on the highly electrophilic carbon atom of the enamide bond $\mathrm{C}=\mathrm{N}$ bearing the methylsulfanyl leaving group of the isothioureas 7. The 1-aminoimidazo[1,5-a]indol-3-ones 8 were easily isolated after quenching the crude reaction mixture with cold deionized water and the insoluble compound $\mathbf{8}$ was collected by filtration and was recrystallized from $\mathrm{EtOH}$.

As can be seen in Table 1, cyclization worked well with methylsulfanyl isothioureas $\mathbf{7 ( a - e )}$ derived from primary amines 4(a-e) while, on the contrary, cyclization failed with compounds $\mathbf{7 ( f , g ) ~ d e r i v e d ~ f r o m ~ c y c l i c ~ s e c o n d a r y ~ a m i n e s ~} \mathbf{5}(\mathbf{a}, \mathbf{b})$ even in the presence of ten-fold excess of lithium hydride. This might be explained by the decrease of the electrophilic character on the carbon atom of the enamide $\mathrm{C}=\mathrm{N}$ bond or by the bulky effect of morpholine-1-yl or $N$-methylpiperazine-1-yl moiety in the possible transient intermediate (Figure 3) which decreases the leaving character of the methylsulfanyl group.

Table. 1: Results for the preparation of compounds $\mathbf{6 ( a - g ) , 7 ( a - g )}$ and 1-amino imidazo[1,5-a]indol-3-one derivatives $\mathbf{8}(\mathbf{a - g})$.

\begin{tabular}{lllll}
\hline Compound & $\mathbf{R}$ & $\mathbf{n}$ & $\mathbf{X}$ & Yield $^{\boldsymbol{a}} \mathbf{( \% )}$ \\
\hline $\mathbf{6 a}$ & $4-\mathrm{Me}$ & 0 & - & 9 \\
$\mathbf{6 b}$ & $\mathrm{H}$ & 0 & - & 9 \\
$\mathbf{6 c}$ & $4-\mathrm{F}$ & 0 & - & 18 \\
$\mathbf{6 d}$ & $3-\mathrm{F}$ & 0 & - & 75 \\
$\mathbf{6 e}$ & $\mathrm{H}$ & 1 & - & 80 \\
$\mathbf{6 f}$ & - & - & $\mathrm{O}$ & 78 \\
$\mathbf{6 g}$ & - & - & $\mathrm{NMe}$ & 75 \\
$\mathbf{7 a}$ & $4-\mathrm{Me}$ & 0 & - & 66 \\
$\mathbf{7 b}$ & H & 0 & - & 52 \\
$\mathbf{7 c}$ & $4-\mathrm{F}$ & 0 & - & 69 \\
$\mathbf{7 d}$ & $3-\mathrm{F}$ & 0 & - & 62 \\
$\mathbf{7 e}$ & H & 1 & - & 65 \\
$\mathbf{7 f}$ & - & - & $\mathrm{O}$ & 59 \\
$\mathbf{7 g}$ & - & - & NMe & 64 \\
$\mathbf{8 a}$ & $4-\mathrm{Me}$ & 0 & - & 32 \\
$\mathbf{8 b}$ & H & 0 & - & 34 \\
$\mathbf{8 c}$ & $4-\mathrm{F}$ & 0 & - & 27 \\
$\mathbf{8 d}$ & $3-\mathrm{F}$ & 0 & - & 52 \\
$\mathbf{8 e}$ & H & 1 & - & 22 \\
$\mathbf{8 f}$ & - & - & $\mathrm{O}$ & - \\
$\mathbf{8 g}$ & - & - & NMe & - \\
\hline
\end{tabular}

${ }^{a}$ Isolated yields.

As can be seen in Table 1, compounds 8(a-e) were isolated in yields ranging from 27 to $52 \%$. The structure identification of these five new 1-aminoimidazo[1,5- $a$ ]indol-3ones 8(a-e) were based on the ${ }^{1} \mathrm{H}$ and ${ }^{13} \mathrm{C}$ assignments and was performed extensive 1D and 2D NMR spectroscopy. Examination of the ${ }^{1} \mathrm{H}$ NMR spectra in DMSO- $d_{6}$ showed that the $\mathrm{CH}=$ proton of the indolyl moiety of 8(a-e) appears at low field $(7.13 \mathrm{ppm}<$ $\left.\delta_{\text {indol }}<7.21 \mathrm{ppm}\right)$.

It is interesting to note that there is only one signal for the NH proton in the ${ }^{1} \mathrm{H}$ NMR spectra of $\mathbf{8}(\mathbf{a}-\mathbf{e})(11.22$ $\mathrm{ppm}<\delta_{\mathrm{NH}}<11.60 \mathrm{ppm}$ ), which strongly indicates the cyclized structure of these compounds. For the methylsulfanyl precursors 7(a-e), we observed two separated signals for the NH protons. As example, in the ${ }^{1} \mathrm{H}$ NMR spectrum of $7 \mathbf{a}$ in DMSO- $d_{6}$, the first $\mathrm{NH}$ broad singulet appears at $11.17 \mathrm{ppm}$ and the second shifted to $11.51 \mathrm{ppm}$. The five new 1 -aminoimidazo [1,5-a]indol-3-ones 8(a-e) were evaluated against five different and representative kinases. Harmine (a natural $\beta$ carboline alkaloid known to be a potent inhibitor of DYRK1A (Tahtouh et al., 2012 and Göckler et al., 2009)) was also used as positive control and its $\mathrm{IC}_{50}$ values were compared with those obtained for the compounds 8. Results given in Table 2 demonstrated that 1-aminoimidazo[1,5- $a$ ]indol-3-ones $\mathbf{8}$ are inactive against DYRK1A, CK1, CDK5/p25, GSK3 $\alpha / \beta$ and CLK1, except for compound $\mathbf{8 b}$ for which an $\mathrm{IC}_{50}$ value of $9 \mu \mathrm{M}$ was determined.

Table 2: Effects of the 1-amino imidazo[1,5-a]indol-3-one derivatives 8(a$\underline{\text { e).on the catalytic activity of four purified protein kinases }}{ }^{a}$.

\begin{tabular}{llllll}
\hline Compound & DYRK1A & CK1 & CDK5/p25 & GSK3 $\alpha / \beta$ & CLK1 \\
\hline $\mathbf{8 a}$ & $>10$ & $>10$ & $>10$ & $>10$ & $>10$ \\
$\mathbf{8 b}$ & 9 & $>10$ & $>10$ & $>10$ & $>10$ \\
$\mathbf{8 c}$ & $>10$ & $>10$ & $>10$ & $>10$ & $>10$ \\
$\mathbf{8 d}$ & - & - & - & - & - \\
$\mathbf{8 e}$ & $>10$ & $>10$ & $>10$ & $>10$ & $>10$ \\
Leucettine L41 & 0.040 & - & - & $>10$ & 0.090 \\
Harmine & 0.029 & 1.5 & $>10$ & $>10$ & 0.072 \\
$(R)$-Roscovitine & 11 & 2.3 & 0.2 & 130 & NT \\
\hline
\end{tabular}

${ }^{a}$ Compounds were tested at various concentrations on each kinase as described in Experimental Section. $\mathrm{IC}_{50}$ values, calculated from the dose-response curves, are reported in $\mu \mathrm{M}$. -, inactive at the highest concentration tested $(10 \mu \mathrm{M}) ;>10$, inhibitory but $\mathrm{IC}_{50}>10 \mu \mathrm{M}$.

\section{CONCLUSION}

In summary, we worked out the synthesis in 5 steps of new 1-aminoimidazo[1,5- $a]$ indol-3-ones 8(a-e) without substituents on the indole moiety. The key step of this sequence is the ring closure by intramolecular sulphur/nitrogen displacement in basic medium with S-methylsulfanyl thioureas 7 derivatives issued from primary amines.

Among these cyclized compounds $\mathbf{8}$, only $\mathbf{8 b}$ presented modest micromolar inhibition activity on DYRK1A $\left(\mathrm{IC}_{50} 9 \mathrm{mM}\right)$. Now, we are interested in further explorations for introduction of molecular diversity with appropriate groups on the indole moiety of compounds $\mathbf{8}$, in order to increase the biological properties of these new 1-aminoimidazo[1,5- $a$ ]indol-3-ones with potential applications in Alzheimer's disease/Down syndrome.

\section{ACKNOWLEDGEMENT}

This research was supported by grants from the 'Fonds Unique Interministériel" (FUI) PHARMASEA project (LM), the "Association France-Alzheimer (Finistère)" (LM) and "Fondation Jérôme Lejeune" (LM). Guillaume BURGY is recipient of a "CIFRE” PhD fellowship.

\section{COMPETING INTERESTS}

LM, JPB and FC are co-inventors on the Leucettine patent (Bazureau et al., 2009). LM is founder of ManRos Therapeutics, which has the exclusive exploitation license for Leucettines. 


\section{REFERENCES}

Abu-El-Halawa R, Sarabi A, El-Abadelah M.M. Facile synthesis of 2-(substituted amino)-4H-thieno[3,2-e]-1,3-thiazin-4-ones. Monatsh. Chem. 2008; 139: 1251-1255. doi: 10.1007/s00706-008-0920-6.

Aiello A, Fattorusso E, Imperatore C, Irace C, Luciano P, Menna M, Santamaria R, Vitalone R. Zorrimidazolone, a bioactive alkaloid from the non-indigenous mediterranean stolidobranch Polyandrocarpa zorritensis. Mar Drugs 2011; 9: 1157-1165. doi: doi:10.3390/md9061157.

Aranda S, Laguna A, de la Luna S. DYRK family of protein kinases: evolutionary relationships, biochemical properties, and functional roles. FASEB J. 2011; 25: 449-462. doi: 10.1096/fj.10-165837.

Bazureau JP, Carreaux F, Renault S, Meijer L, Lozach O. Imidazolone derivatives, preparation method thereof and biological use of same. Patent WO 2009/05032 A2, April 23th 2009.

Chan GW, Mong S, Hemling ME, Freyer AJ, Offen PM, De Brosse CW, Sarau HM, Westley JW. New leukotriene B4 receptor antagonist: leucettamine A and related imidazole alkaloids from the marine sponge Leucetta microraphis. J Nat Prod 1993; 56: 116-121. doi: 10.1021/np50091a016.

Chérouvrier JR, Boissel J, Carreaux F, Bazureau JP. A stereoselective route to 3-methyl-2-methylsulfanyl-5-yliden-3,4-dihydroimidazol-4-one derivatives and precursor of Leucettamine B. Green Chem 2001; 3: 165-169. doi: 10.1039/B101928G.

Chérouvrier JR, Carreaux F, Bazureau JP. Microwave-mediated solventless synthesis of new derivatives of marine alkaloid Leucettamine B. Tetrahedron Lett 2002; 43: 3581-3584. doi: 10.1016/S00404039(00)00575-0.

Cimino G, de Rosa S, de Stefano S, Mazzarella L, Puliti R, Sodano G. Isolation \& X-ray crystal structure of a novel bromo-compound from two marine sponges. Tetrahedron Lett 1982; 23: 767-768. doi: 10.1016/S0040-4020(96)01153-2.

Debdab M, Carreaux F, Renault S, Soundararajan M, Fedorov O, Filippakopoulos P, Lozach O, Babault L, Tahtouh T, Baratte B, Ogawa Y, Hagiwara M, Eisenreich A, Rauch U, Knapp S, Meijer L, Bazureau JP. Design, synthesis and biological evaluation of leucettines, a class of potent CLK and DYRK kinases inhibitors derived from the marine sponge leucettamine B. Modulation of alternative RNA splicing. J Med Chem 2011; 54: 4172-4186. doi: 10.1021/jm200274d.

Debdab M, Renault S, Eid S, Lozach O, Meijer L, Carreaux F, Bazureau JP. An efficient method for the preparation of new analogs of leucettamine B under solvent-free microwave irradiation. Heterocycles 2009; 78: 1191-1203. doi: 10.3987/COM-08-11594.

Göckler N, Jofre G, Papadopoulous C, Soppa U, Tejedor FJ, Becker W. Harmine specifically inhibits protein kinase DYRK1A and interferes with neurite formation. FEBS J 2009; 276: 6324-37. doi: $10.1111 / j .1742-4658.2009 .07346 . x$.

Hagiwara M. Alternative splicing: a new drug target of the postgenome era. Biochim Biophys Acta 2005; 1754: 324-331. doi: 10.1016/j.chembiol.2010.11.009.

Katritzky AR, Singh SK, Bobrov S. Novel synthesis of bicycles with fused pyrrole, indole, oxazole, and imidazole rings. J Org Chem 2004; 69: 9313-9315. doi: 10.1021/jo0485334.

Kutschy P, Suchy M, Dzuriulla M, Takasugu M, Kovacik V. A new approach to imidazo[1,5-a]indole derivatives. Collect Czech Chem Commun 2000; 65: 1163-1172. doi: 10.1135/cccc20001163.
Leclerc S, Garnier M, Hoessel R, Marko D, Bibb JA, Snyder GL, Greengard P, Biernat J, Mandelkow EM, Eisenbrand G, Meijer L. Indirubins inhibit glycogen synthase kinase-3 beta and CDK5/p25, two protein kinases involved in abnormal tau phosphorylation in Alzheimer's disease. A property common to most cyclin-dependent kinase inhibitors? J Biol Chem 2001; 276: 251-260. doi: 10.1074/jbc.M002466200.

Meijer L, Thunnissen AMWH, White A, Garnier M, Nikolic M, Tsai LH, Walter J, Cleverley KE, Salinas PC, Wu YZ, Biernat J, Mandelkow EM, Kim SH, Pettit GR. Inhibition of cyclin-dependent kinases, GSK- $3 \beta$ and casein kinase 1 by hymenialdisine, a marine sponge constituent. Chem Biol 2000; 7: 51-63. doi: 10.1016/S10745521(00)00063-6.

Molina P, Almendros P, Fresneda PM. An iminophosphoranemediated efficient synthesis of the alkaloid leucettamine B of marine of origin. Tetrahedron Lett. 1994; 35: 2235-2236. doi: 10.1016/S00404039(00)76806-7.

Papeo G, Posteri H, Borghi D, Varasi M. A new glycociamidine ring precursor: syntheses of (Z)-hymenialdisine, (Z)-2debromohymenialdisine, and $( \pm)$-endo-2-debromohymenialdisine. Org Lett 2005; 7: 5641-5644. doi: 10.1021/o1052266m.

Primot A, Baratte B, Gompel M, Borgne A, Liabeuf S, Romette JL, Costantini F, Meijer L. Purification of GSK-3 by affinity chromatography on immobilised axin. Protein Expr \& Purif 2000; 20: 394 404. doi: 10.1006/prep.2000.132.

Reinhardt J, Ferandin Y, Meijer L. Purification CK1 by affinity chromatography on immobilised axin. Protein Expr \& Purif 2007; 54:101109. doi: 10.1016/j.pep.2007.02.020.

Roué N, Bergman J. Synthesis of the marine alkaloid leucettamine B. Tetrahedron 1999; 55: 14729-14738. doi: 10.1016/S00404020(99)00918-7.

Tahtouh T, Elkins JM, Filippakopoulos P, Soundararajan M, Burgy G, Durieu E, Cochet C, Schmid RS, Lo DC, Delhommel F, Oberholzer AE, Pearl LH, Carreaux F, Bazureau JP, Knapp S, Meijer L. Selectivity, cocrystal structures, and neuroprotective properties of Leucettines, a family of protein kinase inhibitors derived from the marine sponge alkaloid Leucettamine B. J Med Chem 2012; 55: 9312-9330. doi: 10.1021/jm301034u.

Wan Y, Hur W, Cho CY, Liu Y, Adrian FJ, Lozach O, Bach S, Mayer T, Fabbro D, Meijer L, Gray NS. Synthesis and target identification of hymenialdisine analogs. Chem. Biol 2004; 11: 247-259. doi: doi: 10.1016/j.chem biol.2004.01.015.

$\mathrm{Xu}$ YY, Yakushijin K, Horne DA. Synthesis of C(11)N(5) Marine sponge alkaloids: ( \pm )-hymenin, stevensine, hymenialdisine, and debro- mohymenialdisine. J Org Chem 1997; 62: 456-464. doi: 10.1021/j09619746.

\section{How to cite this article:}

Jean-Pierre BAZUREAU., Exploring the Synthesis of New 1-(4Substitutedphenylamino) imidazo[1,5-a]indol-3-one Derivatives as Cyclized Analogs of Leucettines. J App Pharm Sci, 2014; 4 (06): 025-032. 